\title{
OPPORTUNITY AND CHALLENGE OF ORGANIC CERTIFICATION SYSTEM IN NEPAL
}

\author{
Basanta Rana Bhat (M. Sc. $)^{1}$
}

\begin{abstract}
The demand for organic certification is gradually increasing in Nepal although it is in early stage. Organic certification is a written assurance given by an independent third party about the production methodology and quality of products to confirm special requirements. Certification brings opportunities for protection of local resources, better market access, improvement of worker and consumer health, and eventually enhancement of living conditions of rural communities.
\end{abstract}

The demanding nature of regulatory requirements makes it difficult as well as expensive for local certification initiatives in developing markets to establish themselves to offer export certification. Certification cost, limited awareness of group certification, small and medium-sized farms and inadequate understanding of how organic certification works are some of the constraints for organic certification. Certification Alliance (Cert All), a regional collaboration in certification representing national and international organic certification bodies, addresses the aforementioned challenges. The alliance has recognized the value of collaborating instead of competing. Organic Certification Nepal $(\mathrm{OCN})$, a part of Cert All, offers an internationally accredited inspection and certification service to local operators at a reasonable cost. This paper highlights certification process followed by OCN and potential challenges and opportunities it will likely face.

Key words: Organic Agriculture, Standards, Inspection, Certification, Harmonization

\section{INTRODUCTION}

Organic agriculture is still in the early stages in Nepal. The importance of organic agriculture is being realized not only by farmers who have been using chemical fertilizer and pesticides for the last four decades but also by the policy makers, intellectuals and sensitive citizens after observing the deteriorating situation in the agriculture sector. The continuously increasing price of chemicals (fertilizers, pesticides, etc.) is another important factor for farmers looking for alternatives in order to sustain their farm productivity and livelihoods.

Organic agriculture is a production method which manages the farm and its environment as a single system. It utilizes both traditional and scientific knowledge to enhance the health of agro-ecosystem in which the farm operates. Organic farms rely on the use of local natural resources and the management of the ecosystem rather than external agricultural inputs such as mineral fertilizer and agrochemicals. Organic agriculture, therefore, prohibits synthetic chemicals and genetically modified inputs. It promotes sustainable traditional farming practices that maintain soil fertility.

\section{OBJECTIVES}

The major objectives of this paper are as follows:

- To provide information on processes needed, opportunities and challenges for organic certification in Nepal.

1 Chairperson, Organic Certification Nepal, Kathmandu, E-mail:ecoscentre@wlink.com.np 
- To inform about national initiatives for the establishment of organic certification body in Nepal.

- To highlight the initiation of regional collaboration in organic certification.

\section{WHAT IS ORGANIC CERTIFICATION?}

Organic certification is a procedure by which an independent third party gives a written assurance that a clearly identified process has been methodically assessed to provide adequate confidence for specified products and specified requirements. A certificate is a written guarantee issued by an independent certification agency and it officially states that the production processes or product complies with certain standards.

Certification is used to demonstrate that a product has been produced in a certain way or has certain characteristics complying with a clearly-defined standard. It is mainly used when the producer and the consumer are not in direct contact, for instance in international markets where consumers cannot be easily assured of the quality of a product or its production process, because they never see how and where the products are prepared.

Organic certification requires inspections of the operators (producer/ processor/handler). The purpose of the inspection is to verify that the required conditions are in place to meet the certifying agency's certification criteria or standards. Certification includes inspection of farm fields and processing facilities. Inspections of farm practices include long term soil management, buffering between organic farms and any neighboring conventional farms, product labeling, and record keeping.

\section{CERTIFICATION PROCESS}

Operators applying for organic certification begin by finding a certifying agency. Once the operator chooses an appropriate certification agency, an application package and organic management plan are submitted to the certifying agency. Organic management plans provide a detailed record of all operational practices, methods of farming or handling; the use of substances like fertilizers and pesticides, invoices, breeding records, ledgers, tax returns, and purchase orders.

After the certifying agency reviews the application package and the organic management plan, it inspects the farm and/or facility. Inspectors review fields, equipment, buildings, neighboring land, records of management practices, seed sources, harvesting methods, storage, composting, transportation, and sales practices. The inspector and applicant complete and sign an affidavit before submitting it to the certifier.

A certifying agent or committee reviews the application, organic system plan and the results of the initial inspection.

There are three outcomes to the review process. If approved, the applicant can begin marketing products as organic and may use the organic seal. An applicant with minor discrepancies may be flagged for non-compliance and must address issues or provide additional information before certification. If an applicant has violated standards that cannot be addressed in the short-term, say they haven't upheld organic farming practices, the application is denied. 


\section{OPPORTUNITIES}

Certification brings opportunities for protection of local resources, better market access, improvement of worker and consumer health, and eventually enhancement of living conditions of rural communities. Consumers are increasingly aware of social and environmental problems associated with the production and trade of the food they consume. They want assurance about the quality of the produce they purchase and trust only an independent legal body for the information tagged on the produces. In response to these concerns, private organizations or governments have developed different types of the certification programs.

Certification can help differentiate the preferred organic products from other products, which can be helpful to promote organically grown products in the market. Certification can also result in higher producer prices as consumers are willing to pay higher price for quality products. Organic products thus can raise income of producers and improve the quality of life.

With the increasing population in cities and towns, emergence of an urban middle-class and the growth of supermarkets, national markets for quality products are growing strongly. Producers are also becoming increasingly interested in organic agriculture. Producers shift to organic agriculture for a verity of reasons. Some feel that the use of agrochemicals is bad for their health and the environment, while other producers are attracted by the higher price and the rapidly growing market for many organic products in recent years.

Converting to organic agriculture can be easier and more profitable for producers than conventional agriculture because of the following:

- The availability of local recourses and bio-mass to make organic fertilizers

- The low intensity of agrochemical products used

- The availability of and access to labour (as organic production often demands more labour).

\section{CHALLENGES}

Organic production takes place under different conditions and norms (private standards as well as regulations). Due to the lack of recognition by both government and non-government institutions, certification of international organic product chains has become a complicated and costly service for producer and consumers.

The demanding nature of regulatory requirements makes certification more difficult as well as expensive, especially in developing markets and for export certification. It is hard for local certification bodies to compete with international certification bodies (CBs) in export certification. Local CBs however offer advantages as a service partner to international CBs due to local presence, familiarity of inspectors with local production methods and growing conditions, fluency of staff in local language, and political support for a local business. International $\mathrm{CBs}$ have the possibility of extending their service at competitive rates in the region where they work through collaboration with local CBs. And local CBs can link themselves as part of a service network to offer a one-stop certification service for exports to local operators. 
Whilst most local CBs in developing markets cannot realistically grow into global companies even in the medium term, they may offer enough local advantage to maintain independence as members of an international alliance. Development of service networks, where big and small CBs can collaborate productively, can increase the development and mainstreaming of the organic sector worldwide.

It should nevertheless be noted that collaboration between service organizations in a competitive environment is also about developing strategic relationships to enhance competitive advantage; CBs cannot expect to be partners in more than one similar service network.

Beside regulatory requirements, there are other constraints for organic certification. Some of them are:

- Expensive certification cost

- Limited awareness of group certification among small \& medium farmers

- Small and medium-sized Nepalese organic producers are not able to access international markets

- Inadequate understanding of how organic certification works: Organic certification is a 'production process certification' as opposed to a 'product certification'. Therefore organic certification is a process and not an instant action

- Inadequate technical capacity to develop certifiable production operations

- Increasing number of new regulations

\section{INITIATION OF REGIONAL COLLABORATION IN CERTIFICATION}

Certification Alliance (Cert All) is a regional collaboration in certification representing national and international organic certification bodies, inspectors, producers and development organizations supporting organic movements in the region. While several stakeholders are involved in the process, the alliance has recognized the value of collaborating among them instead of competing. The Certification Alliance represents the commitment of the partner organizations to develop procedures as a certification service network with the aim of offering a low cost one-stop service for organic producers seeking international certification for organic products in the Asia region and elsewhere.

A one-stop service means organic operators can register with a service unit that can facilitate multiple certifications as required for access to European and North American markets as well as within Asia. Collaboration also offers an opportunity for participating partner organizations to mutually share, learn and build competency in inspection and certification, enhancing each other's service performance to secure integrity in the organic supply chain in the interest of producers, the trade and consumers.

The aims and objectives of the Certification Alliance are:

- To facilitate certification required by operators for export markets through Partner Organizations in the countries and regions where they operate.

- To operate a common export inspection service for all Partner Organizations as well as other certification bodies operating in the Asia region and elsewhere.

- To coordinate promotion and marketing of specified inspection and certification services of Partner organizations developed under this agreement.

- To facilitate mutual recognition of certification between Partner Organizations. 
- To facilitate institutional and competency development of Partner Organizations in organic and related inspection and certification services.

- To facilitate knowledge of and market confidence in products certified by Partner Organizations under this agreement in suitable markets.

Organic Certification Nepal (OCN) is one of the founder members of Certification Alliance (Cert All). Being part of Cert All, OCN offers an internationally accredited inspection and certification services to local clients and operators.

\section{CONCLUSION}

Importance of Organic certification is increasing gradually as organic agriculture is getting attention from development stakeholders in Nepal. Nevertheless, there are several challenges and constraints ahead. In order to overcome these challenges, investment in the organic sector is needed. Similarly, the growing divergence in standards and regulations is a threat to the development of this sector. Harmonization has now become a necessity for fostering organic certification and it needs to be saved from self destruction. Many actors including government organizations, NGOs, private sector and farmers should be involved in different steps of organic agriculture promotion and certification. All these efforts from several stakeholders would provide a strong backing in the days to come for the further institutionalization of organic certification in Nepal.

\section{Acknowledgement}

I am thankful to Mr Umesh Lama, Mr Govinda Sharam, Mr Ram Chandra Khanal and Mr Bhola Kumar shrestha for their constant support to bring this paper in a final shape.

\section{References}

Deshmukh, S., 2007. Challenges in organic certification in India. Natural Organic Certification Association. Pune, India

FAO., 2007. A practical manual for producers and exporters from Asia. Bangkok, Thailand

Rana Bhat B., 2007. A National profile on Organic Agriculture of Nepal: proceeding of Regional Conference on Organic Agriculture held at Bangkok, Thailand, 12-15 December 2007: International Trade Centre, UNCTAD/ WTO 